\title{
Currículo de matemática na educação do campo: panoramas e zoons
}

\section{Mathematics curriculum in rural education: panoramic images and images zoomed in}

\author{
Linlya Sachs ${ }^{1}$
}

\begin{abstract}
Resumo
Este artigo tem como objetivo apresentar e discutir maneiras de entender o currículo de matemática na educação do campo, como uma atualização da pesquisa realizada por Barbosa (2014). Para isso, foi feito um levantamento de publicações acadêmicas, em um periódico, em um evento e em dissertações e teses, que aproximem a educação do campo e a educação matemática. A partir da metáfora da fotografia, são feitas imagens panorâmicas, que buscam dar uma ideia do todo. Com a análise dessas publicações, foram constituídas quatro categorias - chamadas de zoons, que focam aspectos relevantes do currículo escolar. A primeira delas entende que é importante "partir da realidade" para chegar ao objeto matemático; a segunda sugere que sejam incluídos nos currículos os "saberes locais"; a terceira afirma que não deve haver especificidade no programa curricular de matemática dessas escolas; e, por fim, a quarta compreende que a escola deveria, também, oferecer uma formação técnica para o trabalho rural.
\end{abstract}

Palavras-chave: Educação matemática; Educação do campo; Currículo; Etnomatemática.

\begin{abstract}
This paper has the purpose to show and to discuss the ways to understand the mathematics curriculum in rural education - this is as an update of Barbosa's research (2014). For that, was made a review of academic publications, in a journal, in an event and in dissertations and theses, that approached education in the field and mathematics education. From the metaphor of the photograph, panoramic images are made, which give an idea of the whole. With that, I compose four categories - called images zoomed in, focusing aspects of scholar curriculum. The first one considers that it's important to start from the student's reality; the second one suggests including local knowledge; the third one asserts that it should not have specificity in mathematics curriculum in rural schools; and, at last, the fourth one proposing that the schools should also offer technical training for rural job.
\end{abstract}

Keywords: Rural Education; Mathematics Education; Curriculum; Ethnomathematics.

\section{Introdução}

A falta de atenção dada à educação do campo é evidente. O estudo realizado pelo Instituto Nacional de Estudos e Pesquisas Educacionais Anísio Teixeira (2007), por exemplo, mostra que são características das escolas do campo: falta de professores efetivos, causando rotatividade; presença de professores sem habilitação, principalmente, em nível superior; baixos salários e elevada carga de trabalho de professores; precariedade das instalações físicas; baixo desempenho escolar dos estudantes, com altos índices de distorção idade-série;

Submetido em: 16/11/2016 - Aceito em: 16/03/2018 - Publicado em: 13/06/2018

${ }^{1}$ Doutora em Educação Matemática pela Universidade Estadual Paulista "Júlio de Mesquita Filho". Professora da Universidade Tecnológica Federal do Paraná, câmpus Cornélio Procópio, Brasil. E-mail: linlyasachs@yahoo.com.br. 
e currículo pouco relacionado com o contexto. Outro fator importante é a ausência de livros didáticos para os anos finais do Ensino Fundamental e Ensino Médio próprios para a educação do campo, já que o Programa Nacional do Livro Didático apresenta uma chamada específica para a educação do campo - o PNLD Campo - que se restringe aos anos iniciais do Ensino Fundamental. Além disso, a educação do campo não tem sido foco das pesquisas da área da educação matemática, como apontam Barbosa, Carvalho e Elias (2014), quando analisaram os trabalhos publicados em dez edições do Encontro Nacional de Educação Matemática e obtiverem um índice de $0,3 \%$ com essa temática.

Algumas mudanças nesse sentido aconteceram nos anos mais recentes, principalmente como consequência do Movimento Por Uma Educação do Campo e do Programa Nacional de Educação na Reforma Agrária (PRONERA). O relatório da II Pesquisa Nacional sobre a Educação na Reforma Agrária (IPEA, 2015) indica que, de 1998 a 2015, por meio de parcerias com universidades, o PRONERA formou um número significativo de professores em todo país, nas diversas áreas. Diversas políticas públicas foram lançadas para a educação do campo, especialmente na primeira década e início da segunda dos anos 2000. Como consequência, houve um aumento nas pesquisas sobre o tema - como mostro aqui.

Este texto é uma atualização dos panoramas traçados em minha pesquisa de doutorado (Barbosa, 2014) e tem como objetivo apresentar e discutir maneiras de entender o currículo de matemática na educação do campo. Esses panoramas, presentes aqui, referem-se a publicações acadêmicas, em um periódico, em um evento e em dissertações e teses, que aproximem a educação do campo e a educação matemática. Trata-se de uma atualização, pois, nos últimos anos, há novas publicações sobre esse assunto, devido, principalmente, à criação e à consolidação de cursos de Licenciatura em Educação do Campo com habilitação em Matemática.

Ser professor de matemática no contexto da educação do campo envolve a questão curricular: que conhecimento valorizar nas aulas de matemática e com quais propósitos? Partilho o entendimento de Silva (2010), ao afirmar que “[...] a pergunta 'o quê?' nunca está separada de uma outra importante pergunta: 'o que eles devem ser?' ou, melhor, 'o que eles ou elas devem se tornar?'. Afinal, um currículo busca precisamente modificar as pessoas que vão 'seguir' aquele currículo" (p. 15). Apresento, então, algumas formas de se entender o currículo de matemática na educação do campo, presentes nas publicações mapeadas.

Como apontam Thiesen e Oliveira (2012), é necessário que, nas discussões a respeito da educação do campo, se construa uma concepção própria de currículo, o que ainda não foi feito e que tem como consequência a apropriação do Estado desse território ainda não habitado, com propostas educacionais "prontas e acabadas" (p. 26). Nos trabalhos da educação matemática, a situação não é diferente; aliás, talvez pela escassez de trabalhos, seja ainda um pouco mais crítica.

Este artigo está estruturado da seguinte maneira: inicio apresentando as bases teóricas da pesquisa; em seguida, mostro brevemente os procedimentos metodológicos adotados e as imagens panorâmicas constituídas; e, por fim, discuto as categorias construídas a partir dos Zetetiké, Campinas, SP, v.26, n.2, mai./ago., 2018, p.404-422 ISSN 2176-1744 
panoramas, chamadas aqui de zoons.

\section{Bases teóricas}

Três bases teóricas fundamentam esta pesquisa: a educação do campo; a etnomatemática; e as questões curriculares.

No que se refere à educação do campo, é importante situar esta pesquisa após o Movimento Por Uma Educação do Campo. Munarim (2008) considera o $1^{\circ}$ Encontro Nacional de Educadoras e Educadores da Reforma Agrária, em 1997, como um marco nesse processo. Com a realização da $1^{\mathrm{a}}$ Conferência Nacional por uma Educação Básica do Campo, no ano seguinte, é alterada a nomenclatura usada pelos movimentos sociais e, posteriormente, pelo governo para se referir à educação - antes rural e, agora, do campo. Mas, mais do que uma simples mudança de termos, trata-se de uma mudança de concepção.

A "educação rural", carregada de descaso e de subordinação ao capital, é substituída por uma nova concepção de educação, a "educação do campo"; esta, para Munarim (2008), carrega diferentes preceitos políticos e pedagógicos. Assim, a mudança seria tamanha que não "suportaria" os mesmos termos como referência.

Um ponto importante é que a educação do campo tem sua origem com os movimentos sociais, sendo o Movimento dos Trabalhadores Rurais Sem-Terra (MST) o seu maior expoente. Caldart (2012) destaca, nesse sentido, a "pedagogia da luta social" (p. 335). Como a autora afirma,

[...] nas pedagogias mais tradicionais, a educação é vista exatamente no contraponto da luta, sendo a ordem seu valor mais precioso. Por isso, a educação é vista como sinônimo de socialização passiva, de integração à sociedade, de aprendizado da obediência ou até do conformismo social (Caldart, 2012, p. 344, grifo da autora).

Questionar a ordem, ao invés de obedecê-las tranquilamente, está nessa lógica.

Outra importante matriz na educação do campo, vinda dos movimentos sociais, é a "pedagogia da organização coletiva" (Caldart, 2012, p. 346). Em oposição ao individualismo, reforçado por sistemas de avaliação competitivos, busca-se uma educação que ocorra no coletivo, com participação ampla e que as ações sejam tomadas pelo grupo. A pesquisadora Gelsa Knijnik, em entrevista por mim realizada (Barbosa, 2014, p. 37), ressalta esse aspecto: "qual a grande diferença das escolas do movimento? Que lá tem um projeto coletivo [de sociedade]".

Por outro lado, as políticas públicas (por exemplo, MEC, 2002, 2008) apropriaram-se do termo e de algumas propostas da educação do campo. Caldart (2009) indica contradições decorrentes disso:

A Educação do campo inicia sua atuação desde a radicalidade pedagógica destes movimentos sociais e entra no terreno movediço das políticas públicas, da relação com um Estado comprometido com um projeto de sociedade que ela combate, se coerente for com sua materialidade e vínculo de classe de origem (Caldart, 2009, p. $38)$. 
A respeito da etnomatemática, de acordo com D'Ambrosio (2004), ela busca entender e conhecer o saber e o fazer matemático de culturas marginalizadas. Também, além disso, "procura entender o ciclo da geração, organização intelectual, organização social e difusão desse conhecimento" (p. 45). No caso desta pesquisa, busco apresentar e discutir maneiras de entender a organização intelectual, social e a difusão desse conhecimento no currículo, especificamente de matemática, na educação do campo.

As escolas têm papel importante quando se trata de organização intelectual e de difusão do conhecimento. Os currículos dessas escolas contêm os saberes considerados (por um grupo social, por uma comunidade, por um professor) necessários aos seus estudantes - e, consequentemente, aqueles saberes excluídos dos currículos são considerados menos importantes ou menos necessários a eles.

Compartilho dos questionamentos de Knijnik (2004b, p. 32) sobre a etnomatemática:

Entre as questões que têm sido objeto de discussão - e hoje se constituem em desafios para o campo da Etnomatemática - está aquela que diz respeito à diversidade cultural. Como entendê-la, sem cair na armadilha de uma visão essencialista da diferença? Como lidar com a diversidade de culturas, sem folclorizá-las? Aqui, o que está em jogo é evitar o elogio ao exótico, ao diferente (é claro) "de nós".

Knijnik (2004a), ainda, reforça a importância de pensar sobre o currículo:

Nosso papel nestes processos de inclusão ou exclusão de conhecimentos no currículo escolar é, antes de tudo, e sobretudo, político. Tais processos, definindo quais grupos estarão representados e quais estarão ausentes na escola são, ao mesmo tempo, produto de relações de poder e produtores destas relações: produto de relações de poder, pois são os grupos dominantes que têm o capital cultural para definir quais os conhecimentos que são legítimos para integrar o currículo escolar; são também produtores de relações de poder, porque influem, por exemplo, no sucesso ou fracasso escolar, produzem subjetividades muito particulares, posicionando as pessoas em determinados lugares do social e não em outros. Estes lugares não estão, de uma vez por todas, definidos. O campo da Educação Matemática é também um campo possível de contestação. Por isto, político.

Nesse sentido - político -, concordo com o entendimento de Caldart (2009, p. 37), que afirma que aqueles que trabalham em nome da educação do campo precisam se posicionar teoricamente, mas, sobretudo, politicamente.

Abandono, aqui, qualquer modo de entender o currículo que esteja apoiado em neutralidade. A seleção de conteúdos, conhecimentos, saberes está pautada em um objetivo anterior, que é o de formar pessoas, transformá-las.

Entendo que o currículo materializa o poder em uma sociedade ou cultura. Silva (2010, p. 147) afirma: “[...] o currículo é, definitivamente, um espaço de poder”. Esse poder envolve tanto o poder capitalista, o poder das classes sociais dominantes, o poder da estrutura de sociedade, quanto o poder mais sutil, cultural, de gênero, étnico. Para o autor, o primeiro o poder econômico e político - é atacado pelas teorias críticas de currículo, enquanto o segundo - o poder revelado no discurso - é o alvo das teorias pós-críticas. 
Essas teorias, críticas e pós-críticas, não se opõem, como pode parecer de relance; nas teorias pós-críticas, a crítica se mantém, mas com outras justificativas - menos baseadas em metanarrativas (como o marxismo) e mais baseadas no discurso. Michael Apple, em entrevista dada a Silva, Marques e Gadin (2012, p. 183), por exemplo, afirma transitar entre as duas:

No meu próprio trabalho tenho tentado incorporar tanto as tradições marxistas quanto algumas tradições pós-estruturalistas. [...] não vamos dar como pressuposto que as novas teorias que tratam da questão do discurso vão substituir os ensaios do marxismo e de suas tradições... Foucault nunca disse que Marx era estúpido. Esta é a minha posição.

Em Sachs (2017), é melhor discutida uma articulação entre essas bases teóricas, concluindo que diferentes teorias curriculares dão sustentação a diferentes implicações pedagógicas da etnomatemática na educação do campo. Em especial, as teorias críticas e as pós-críticas relacionam-se mais fortemente com a etnomatemática, podendo, por um lado, reconhecer que os conhecimentos que têm espaço nos currículos estão revestidos de poder e, por outro, questionar o que é considerado verdadeiro e o que não é.

Com base no tripé aqui apresentado - educação do campo, etnomatemática e questões curriculares - foram analisadas as produções que tratam da educação matemática no contexto da educação do campo. A seguir, apresento os procedimentos metodológicos da pesquisa e as imagens panorâmicas encontradas.

\section{Procedimentos metodológicos e imagens panorâmicas}

Duas partes importantes desta pesquisa são apresentadas a partir da metáfora da fotografia: primeiramente, são feitas fotografias panorâmicas, isto é, de uma maneira mais ampla, mais abrangente, sem aprofundamentos, sem análises, são apresentadas algumas dimensões do tema aqui tratado, que relaciona a educação matemática e a educação do campo; em seguida, as fotografias utilizam o recurso do zoom, ou seja, sem perder o foco, aproxima-se a imagem e pode-se ver com mais proximidade aquilo que se observa e, então, aumenta-se a riqueza de detalhes ${ }^{2}$.

O que chamo de imagens panorâmicas são paisagens das publicações que tratam da educação matemática no contexto da educação do campo, que podem dar uma ideia do todo. Essas paisagens foram atualizadas da pesquisa que realizei no doutorado (Barbosa, 2014), considerando novas publicações.

Para essas imagens panorâmicas, foi necessário delimitar os locais de pesquisa.

O primeiro deles foi a escolha de um periódico para a pesquisa: o Boletim de Educação Matemática (BOLEMA). A escolha deu-se por sua classificação no sistema Qualis da Coordenação de Aperfeiçoamento de Pessoal de Nível Superior (CAPES) como A1 na área de Ensino e por ser um periódico brasileiro (fato importante, pela pesquisa tratar da

\footnotetext{
${ }^{2}$ Essa metáfora da fotografia, com imagens panorâmicas e zoons, foi desenvolvida em Barbosa (2014).
} 
educação do campo, originária de movimentos sociais brasileiros), específico da educação matemática.

Pesquisei em todas as edições do periódico de 1985 a 2016, de número 1 a 55, totalizando 60 edições. Para busca de artigos que tratassem do tema da educação do campo, utilizei os seguintes filtros e suas variações no plural: "educação do campo", "educação rural”, "educação no campo", "escola do campo", "escola rural”, "educação popular”, "escola ativa", "escola itinerante", "assentamento", "acampamento", “agricultura”, "sem terra", "MST", "reforma agrária", "agrícola", "camponês" e "rural".

Esses termos foram escolhidos com base no Dicionário da Educação no Campo (Caldart, Pereira, Alentejano, Frigotto, 2012), que os apresenta como entradas ou como expressões presentes nos verbetes dessas entradas.

De um total de 636 artigos do periódico, após a aplicação desses filtros e a leitura dos previamente selecionados, excluindo os que não tratavam da educação do campo e de educação escolar, obtive nove artigos. Essa é a primeira imagem panorâmica encontrada. Em termos quantitativos, as publicações que tratam da educação do campo no BOLEMA representam $1,4 \%$ do total de artigos publicados no periódico no período indicado. Vale destacar que, quatro dessas publicações concentram-se nos últimos quatro anos e todas neste século XXI. Esses números são prováveis reflexos das ações dos movimentos sociais no final dos anos 1990 e da posterior criação de políticas públicas para a educação do campo no país.

O segundo local de pesquisa foi um evento da educação matemática: o Encontro Nacional de Educação Matemática (ENEM). É aqui que se constitui a segunda imagem panorâmica.

A escolha desse evento deu-se por alguns motivos: o ENEM já teve 12 edições (de 1987 a 2016); tem abrangência nacional; e os números de participantes e de trabalhos apresentados são altos. Como afirma a Sociedade Brasileira de Educação Matemática (http://www.sbembrasil.org.br/enem2016/apresentacao.html): "Este evento é o mais importante no âmbito nacional, porque congrega o universo dos segmentos envolvidos com a Educação Matemática: professores da Educação Básica, Professores e Estudantes das Licenciaturas em Matemática e em Pedagogia, Estudantes da Pós-graduação e Pesquisadores".

Com posse dos anais das 12 edições do evento, tive acesso aos textos das comunicações científicas, dos relatos de experiência, dos pôsteres, das conferências, das palestras, dos minicursos e das mesas-redondas. Todos eles, denomino "artigos". Apliquei os mesmos filtros citados anteriormente e, após uma análise mais cuidadosa, excluindo aqueles que não tratam da temática da educação do campo e que não tratam da educação escolar, obtive como resultado 73 artigos, de um total de 7477 - o que equivale a $0,98 \%$.

Uma informação importante é o aumento significativo de publicações com essa temática nas duas últimas edições do evento (de 2013 e de 2016): 82,2\% dos artigos concentram-se nessas edições. Além das razões já citadas anteriormente, a criação dos cursos 
de Licenciatura em Educação do $\mathrm{Campo}^{3}$, com a primeira chamada pública em 2009, influenciou esse resultado. É possível perceber isso nas temáticas dos artigos, sendo muitos deles desenvolvidos no âmbito de cursos de Licenciatura em Educação do Campo e outros que tratam das especificidades desses cursos.

O terceiro local de pesquisa, e a terceira imagem panorâmica, foi o banco de teses da CAPES, que reúne informações sobre dissertações e teses defendidas no país. Essas informações (título, autoria, instituição, orientador e resumo) são fornecidas pelos programas de pós-graduação à CAPES.

No período em que foi feita a primeira parte da pesquisa, em 2013, estavam disponíveis informações relativas a dissertações e teses defendidas de 2005 a 2012; já no momento de atualização da pesquisa, estavam disponíveis informações relativas a dissertações e teses defendidas de 2013 a outubro de 2016. Dessa forma, a pesquisa se refere ao período de 2005 a 2016.

Fiz a busca a partir de palavras-chave: primeiramente, com ambos os termos "rural" e "matemática"; em seguida, com os termos "educação do campo" e "matemática"; por fim, com "escola do campo" e "matemática". Em todos os casos, analisei se essas palavras ou expressões estavam presentes no texto todo e excluí os casos impertinentes à pesquisa. Com a leitura dos resumos e, em alguns casos, de trechos do trabalho completo, determinei quais tratavam da educação escolar, excluindo as dissertações e teses que não tratavam desse contexto. Obtive, dessa forma, 70 trabalhos.

Não são todas essas dissertações e teses referentes a programas de pós-graduação em Educação, Educação Matemática ou, mais amplamente, pertencentes à área de Ensino da CAPES; além de áreas como Psicologia e Ciências da Linguagem, destaco também a presença de dissertações do Mestrado Profissional em Matemática em Rede Nacional (PROFMAT).

Ainda, é possível perceber que, dos 70 trabalhos, apenas oito são teses de doutorado, sendo os demais, dissertações de mestrado acadêmico (48) e profissional (14).

Dentre os estados com maior produção na área, estão Rio Grande do Sul, com 14 publicações, São Paulo, com 11 publicações, e Minas Gerais e Pernambuco, com seis publicações cada.

\footnotetext{
${ }^{3}$ O edital de 2009 (SECAD, 2009) lançou a chamada para as seguintes áreas de habilitação: Linguagem e Códigos; Ciências Humanas e Sociais; Ciências da Natureza e Matemática; e Ciências Agrárias. Já no edital seguinte, lançado em 2012 (SECADI, 2012), a área "Ciências da Natureza e Matemática" foi dividida em "Ciências da Natureza" e "Matemática". Várias questões curriculares podem ser colocadas a respeito dessa separação, como quais as razões de a Matemática ser a única área que não envolveu mais de uma disciplina (como costumam ser os cursos de Licenciatura e as aulas no Ensino Fundamental e, mais especificamente, no Ensino Médio) e a quebra de uma proposta multidisciplinar que valeria para as diversas disciplinas. Em Antunes-Rocha (2009), sobre o curso oferecido pela Universidade Federal de Minas Gerais, é apresentada uma discussão sobre as dificuldades em elaborar o curso por áreas mais abrangentes. Não foi objetivo desta pesquisa, porém, aprofundar nessas questões.
} 
O crescimento do número de pesquisas com a temática da educação do campo também foi visível nas dissertações e teses: 82,9\% foram publicadas entre 2010 e 2016.

De posse de todos esses trabalhos - artigos do BOLEMA, do ENEM e dissertações e teses - utilizei os procedimentos metodológicos da Análise Textual Discursiva, descrita por Moraes e Galiazzi (2007). Eles constituíram, então, o corpus, que é o conjunto dos documentos a serem submetidos aos procedimentos analíticos da pesquisa. Fazem parte do corpus, portanto, nove artigos publicados no BOLEMA, 73 artigos apresentados no ENEM e 70 dissertações ou teses (sendo oito teses de doutorado, 48 dissertações de mestrados acadêmicos e 14 dissertações de mestrados profissionais).

Iniciou-se o processo de desconstrução dos textos, com o recorte de trechos que fossem potencialmente interessantes para a posterior categorização. Fiz uma codificação para essas unidades, de modo que eu fosse capaz de encontrar, quando desejasse, seu contexto. Essas unidades - que podem ser comparadas aos pixels de uma fotografia - compuseram quatro categorias criadas por mim, não excludentes entre si - os zoons.

Esses zoons foram sendo constituídos no decorrer de toda a pesquisa, com percepções pessoais sobre aproximações e distanciamentos de alguns entendimentos nesses textos do corpus. Classifiquei, então, as unidades conforme as categorias já estabelecidas, os zoons. Inicialmente, eu tinha uma ideia do que seria cada zoom, o que faria parte dele, mas não sabia exatamente o que iria compô-lo, nem como denominá-lo. Isso aconteceu durante o processo de análise.

Algumas publicações selecionadas têm a pesquisa realizada em escolas situadas no meio rural, mas nada trazem de discussão sobre esse fato, nem, ao menos, alguma indicação que a educação nessas escolas deva ser semelhante à educação das escolas urbanas. Essas não farão parte da análise e criação dos zoons, pois fogem do objetivo deste artigo.

Como afirmam Moraes e Galiazzi (2007, p. 113), o corpus "representa uma multiplicidade de vozes se manifestando nos discursos investigados" e é isso que pretendo explicitar com os zoons.

\section{Zoons}

As imagens com zoom - ou, simplesmente, os zoons - focam aspectos relevantes do currículo escolar, especificamente de matemática, na educação do campo. Não são necessariamente focos excludentes os que serão apresentados aqui; possivelmente alguns deles coexistam em uma mesma fotografia.

Utilizo aqui os mesmos nomes para os zoons presentes em minha tese de doutorado (Barbosa, 2014), que vieram a partir de entrevistas que aqui não serão apresentadas. As falas resumem os zoons, mas são acompanhadas de uma descrição, em que pude relacioná-los com teorias e exemplificá-los com as unidades. A atualização da pesquisa, feita para este artigo, foi pautada nesses zoons e os muitos novos trabalhos analisados passaram a compô-los. 
São quatro zoons: o primeiro deles, denominado "Quando eu vou, às vezes, dar um exemplo, eu começo a citar boi, hortaliças, verdura", entende que é importante "partir da realidade" para chegar ao objeto matemático, em escolas do campo; o segundo, "Vamos aos saberes locais, porque eles também foram acumulados pela humanidade”, ao contrário, questiona os conhecimentos presentes nos programas curriculares e sugere que neles sejam incluídos os "saberes locais"; o terceiro, denominado "Matemática é matemática, ou tem matemática do campo?", afirma que não deve haver especificidade no programa curricular de matemática de escolas do campo; e, por fim, o quarto, "A escola poder ajudar nessa formação deles, ajudar na família, no cultivo, no plantio”, compreende que a escola do campo deveria, também, oferecer uma formação técnica para os trabalhos rurais.

"Quando eu vou, às vezes, dar um exemplo, eu começo a citar boi, hortaliças, verdura"

A frase que nomeia este zoom é de uma professora de uma escola do campo entrevistada (Barbosa, 2014) e representa grande parte dos entendimentos a respeito da educação do campo, apresentados aqui.

Ao abordar o programa curricular das escolas, especificamente, no que se refere à matemática, percebo que é comum entendê-lo como um artefato predefinido; nessa perspectiva, o programa está posto, cabendo ao professor pensar e elaborar a forma de condução de suas aulas para atingir os conteúdos que lá estão. Diante disso, nessa perspectiva, o programa curricular não é alterado, mas os métodos de trabalhá-lo, sim, podem ser repensados.

No contexto da educação do campo, esse repensar aparece muito forte, em especial, com práticas pedagógicas que levem em conta os saberes camponeses e as situações cotidianas dos estudantes.

Neste zoom, mostro alguns trechos do corpus que entendem o programa curricular das escolas do campo como o mesmo de qualquer outra escola, com os mesmos conteúdos, mas que "partem da realidade" para chegar ao objeto matemático. O cotidiano, a vida real, o campo são elementos de "motivação", de "aplicação", de "contextualização" ou que devem ser "traduzidos" para a matemática escolar, presente nos currículos.

Nos artigos do ENEM, há alguns casos com este viés de partir da realidade para chegar ao conhecimento matemático escolar, como o de Justi e Bennemann (2016, p. 8):

Nessa atividade para uma melhor interação do educando, foi disponibilizado um texto contextualizado, foto de um resfriador de leite em forma cilíndrica e também conexões de plástico, emendas internas e externas, de canos e mangueiras de diversos diâmetros, para manuseio e interpretação. As relações matemáticas abordadas foram: unidades de medidas, polegadas e submúltiplos do metro, transformação de unidades; estudo do diâmetro; estudo do $\pi(\mathrm{pi})$; estudo da área do círculo; razão entre áreas; e noção de cilindro e seu volume.

A dissertação de Costa (2012) traz, em vários momentos, afirmações que refletem o entendimento de que os elementos do cotidiano rural - no caso, ribeirinho - são meios para Zetetiké, Campinas, SP, v.26, n.2, mai./ago., 2018, p.404-422 
atingir o conteúdo matemático que costuma fazer parte dos programas curriculares, como no que segue: "No contexto da educação do campo determinados elementos disponíveis na própria comunidade como as plantações, as construções, as crenças podem servir como elementos instigadores para o processo de ensino da matemática na escola” (p. 48).

A dissertação de Matos (2014), também, vai nesse sentido. A contextualização tornaria o ensino de função afim "mais interessante" para o estudante do curso técnico de Agroecologia:

Uma saída para se tornar o ensino das funções afins mais interessante para o público do curso de agroecologia é aliar o ensino de funções às vivências do pequeno agricultor, além das vivências dos alunos que terão disciplinas técnicas nas quais a função afim se aplica como modeladora de fenômenos físicos e como suporte à resolução de problemas (Matos, 2014, p. 77).

Entendo que, nessa perspectiva, a escola e as aulas de matemática objetivam o conhecimento matemático curricular - e não o conhecimento cotidiano - e criam-se meios para atingi-lo. Assim afirma Seckler (2010, p. 11), em sua dissertação: “[...] um trabalho escolar apoiado no cotidiano dos alunos pode levá-los a uma maior motivação para o estudo".

Vejo aproximações entre essas propostas e a abordagem multiculturalista nas perspectivas liberal e humanista, que para Silva (2010, p. 88-89), baseia-se na tolerância, no respeito e na harmonia. $\mathrm{O}$ autor afirma que críticas são feitas a essa linha, visto que as relações de poder se mantêm, mesmo com a tolerância e com o respeito - que, apesar de desejáveis, não alteram a assimetria ou a desigualdade das relações sociais. Assim, “[...] o multiculturalismo não pode ser separado das relações de poder que, antes de mais nada, obrigaram essas diferentes culturas [...] a viverem no mesmo espaço" (Silva, 2010, p. 85).

Em seu artigo do ENEM, Lopes (2016, p. 7) reflete sobre essa "simples" troca de palavras:

Os professores quando fazem as trocas de palavras busca por linhas de fuga, busca a expansão do mundo de seu aluno. Se é certo ou errado, ainda não se sabe. Se estiver errado, quem culpar? [...] A pergunta é: quem ali não está lutando por sua, mas também pela sobrevivência de uma escola? Não se trata de certo ou errado. Mas pensar a formação com algo inacabado é pensar uma formação fora das caixinhas, talvez de modo inadequado, o professor de Filosofia faz isso, quando aceita as aulas de Matemática. Afinal é um sobrevivente. O dia a dia de uma escola, não cabe em papeis. Não cabe em 4 horas de palestra. A formação se dá na (de)formação, na (trans)formação, se ela não acontece assim, ela acontece em um molde. E formação é mais.

Knijnik (2001), em artigo do BOLEMA, critica essa forma de lidar com os conhecimentos: "Não se tratava de realizar traduções que se restringissem a equivalências numéricas [...]. Uma abordagem que se restringisse a este tipo de operação estaria exatamente reduzindo todo o trabalho à Matemática acadêmica formal [...]” (p. 12).

O título deste zoom resume, grosso modo, esse modo de entender a educação do campo. Esta foi a resposta dada pela professora entrevistada (Barbosa, 2014), quando questionada sobre o enunciado, discutido por Knijnik e Duarte (2010), de que "é importante Zetetiké, Campinas, SP, v.26, n.2, mai./ago., 2018, p.404-422 
trazer a 'realidade' do aluno para as aulas de matemática": "Ah, isso é muito importante. Não só em matemática, mas em todas as disciplinas. É como eu te falei, eu procuro adaptar, então, quando eu vou às vezes dar um exemplo, eu começo a citar boi, hortaliças, verduras $[\ldots] "$.

"Vamos aos saberes locais, porque eles também foram acumulados pela humanidade"

É com essa resposta - o título desta seção - que a professora e pesquisadora Gelsa Knijnik, em entrevista realizada em minha pesquisa de doutorado (Barbosa, 2014), rebate à seguinte afirmação de Basso e Bezerra Neto (2012, p. 7): “[...] a maioria dos trabalhadores rurais compõe a classe dos trabalhadores e que tem direito ao acesso aos conhecimentos produzidos pela humanidade e não a uma educação apartada daquela oferecida no meio urbano".

A fala de Gelsa sintetiza o entendimento de diversos pesquisadores a respeito da educação do campo; a escola, como local privilegiado para acesso ao conhecimento, deveria também incluir em seus currículos os saberes que historicamente deles foram excluídos. Aí entram os chamados "saberes locais".

Nessa perspectiva, o programa curricular deixa de ser inquestionável - como no zoom anterior - e possibilita mudanças, na medida em que ele é reconhecido como um espaço político.

Diferentemente dos que entendem que o conhecimento da vida cotidiana dos estudantes das escolas do campo pode servir como base para alcançar o conhecimento dito científico, aqui está presente uma equiparação de valor entre esses saberes que serão incorporados ao programa curricular e aqueles que lá já estão. Assim, não se trata de adicionar a ele informações de outras culturas, como a do campo, a título de curiosidade, de informação ou de folclore, mas trata-se de torná-lo, de fato, um território político (Silva, 2010).

Lopes Filho (2014, p. 93), em sua dissertação, afirma a diferença entre os saberes da escola e das práticas agrícolas:

As técnicas de resolução dos problemas contidos nas cinco atividades apresentadas demonstram que há saberes matemáticos relacionados às práticas agrícolas, mas que esses saberes não são reconhecidos como um saber escolar, da mesma forma que o saber escolar também não é reconhecido dentro do saber matemático.

Este zoom é uma resposta - e seu título, de fato, é - à Pedagogia Histórico-Crítica. Algumas de suas ideias estão sintetizadas nas palavras de Saviani (2011, p. 14):

[...] a escola é uma instituição cujo papel consiste na socialização do saber sistematizado. Vejam bem: eu disse saber sistematizado; não se trata, pois, de qualquer tipo de saber. Portanto, a escola diz respeito ao conhecimento elaborado e não ao conhecimento espontâneo; ao saber sistematizado e não ao saber fragmentado; à cultura erudita e não à cultura popular. 
Porém, alguns trabalhos mostram que nem sempre o estudante conhece o que para seus pais, vizinhos, ou outros de sua comunidade é habitual. Na dissertação de Fontana (2006, p. 14), isso é observado: “[...] alguns grupos de agricultores produziam uma matemática própria do campo, a qual a escola do meio rural desconhecia. Questionávamos, ainda sem encontrar resposta, sobre o modo como introduzi-la num currículo oficial".

Por isso, e como forma de respeito a esses saberes, a proposta é incluí-los no currículo. Vemos isso em alguns artigos do ENEM, como o de Oliveira (1998, p. 216), que diz que "a investigação envolveu não só a recuperação dos saberes populares do meio rural, mas esteve dirigida para a possibilidade de escolarizá-los”.

Souza (2016, p. 8), em seu artigo do ENEM, constata que essa inclusão de saberes não acontecia na escola investigada, na zona rural de Quirinópolis-GO: "Durante as observações não percebemos práticas pedagógicas de professores de Matemática que priorizassem a conexão do conhecimento matemático com outros saberes nem com a própria realidade da comunidade rural".

No caso dos cursos de Licenciatura em Educação do Campo, essa questão curricular também se coloca para disciplinas de conteúdo matemático, como mostram Sachs e Elias (2016, p. 452), em artigo do BOLEMA:

O contexto social camponês é trazido em grande parte dos projetos de curso, nos itens objetivo e perfil do egresso, sendo que muitos deles deixam explícita a importância em articular a formação do professor com os saberes próprios do campo. Porém, no que se refere às ementas dos componentes curriculares, esse aspecto é menos evidente.

Assim, este zoom trata de entendimentos que questionam os programas curriculares, propondo que os saberes locais façam parte dos temas ou conteúdos a serem abordados na educação do campo.

\section{"Matemática é matemática, ou tem matemática do campo?"}

Deve haver especificidade no currículo de matemática de uma escola do campo? Esse é um ponto de pouco consenso no corpus. Enquanto alguns afirmam que é essencial que o currículo seja próprio para cada escola, outros entendem que os conteúdos a serem desenvolvidos em qualquer escola devem ser os mesmos.

Bourdieu (2007) evidencia que o currículo e a linguagem escolar estão fundamentados na cultura dominante, no saber erudito. Assim, os membros da classe social dominante têm acesso privilegiado a essa cultura, no âmbito familiar; enquanto aqueles das classes sociais mais baixas, além de não ter acesso a ela em suas famílias, têm acesso a outras culturas que, por sua vez, são desprezadas nas escolas.

Essa problemática, no que se refere ao currículo escolar, pode sugerir duas saídas: uma seria a mudança daquilo que compõe o programa curricular das escolas, isto é, um currículo baseado nas culturas dominadas; outra seria um programa curricular que, realmente, 
contemple as condições que apenas os oriundos das classes dominantes têm em suas famílias, para os estudantes das classes sociais menos favorecidas.

A primeira opção abordei no zoom anterior e a segunda, tratarei aqui.

Para Bourdieu (2007), vale a segunda opção: a instituição escolar deve "desempenhar a função que lhe cabe, de fato e de direito, ou seja, a de desenvolver em todos os membros da sociedade, sem distinção, a aptidão para as práticas culturais que a sociedade considera como as mais nobres" (p. 62).

Um professor e pesquisador que entrevistei (Barbosa, 2014), também me responde dessa forma, quando questionei se ele acredita que deva haver uma educação específica nas escolas do campo: "Não, porque a minha referência, como é o marxismo, eu acho que a educação tem como princípio universalizar o que foi produzido socialmente”. E, ainda, com relação à matemática, afirma que o programa curricular deve ser o mesmo, mas voltado a responder a questões que se colocam em sua vida no campo: "Porque se eu vou ensinar Matemática, na educação do campo, Matemática é Matemática, ou tem Matemática do Campo? Oи eи utilizo o instrumental matemático, para responder alguns problemas que se apresentam no campo?" - e é com esse trecho que nomeio esta seção.

Com esse entendimento, no corpus, encontro textos que remetem à "equiparação" entre escolas do campo e escolas urbanas, como na fala de uma professora, na dissertação de Fontana (2006) "Mas não que isso, que o nosso currículo tenha que ser diferente porque a gente é do interior" (p. 86). Também, foi constatado no artigo do ENEM, de Lima e Carvalho (2010), que "as escolas rurais, como todas as outras, seguem um currículo único preestabelecido pela secretaria da educação" (p. 2).

A Pedagogia Histórico-Crítica, já citada anteriormente, embasa este zoom:

Se as escolas se limitarem a reiterar a cultura popular, qual será sua função? Para desenvolver cultura popular, essa cultura assistemática e espontânea, o povo não precisa de escola. Ele a desenvolve por obra de suas próprias lutas, relações e práticas. O povo precisa da escola para ter acesso ao saber erudito, ao saber sistematizado e, em consequência, para expressar de forma elaborada os conteúdos da cultura popular que correspondem aos seus interesses (Saviani, 2011, p. 69-70).

A dissertação de Feyh (2013), ressalta o acesso a esse conhecimento sistematizado: "Nessa direção a proposta de Modelagem Matemática apresentada nesse registro escrito como proposta pedagógica de ensino e pesquisa escolar, considera saberes locais pertinentes a Educação do Campo, para a partir desses, apresentar Conhecimentos Científicos produzidos historicamente pela humanidade" (p. 6, apêndice B).

Neste zoom, portanto, está presente a ideia de que a matemática - que deve ser abordada nos currículos escolares - é única; não há "matemática do campo". Trata-se de dar acesso à matemática nos diferentes meios e, entre eles, estão as escolas do campo. 
"A escola poder ajudar nessa formação deles, ajudar na família, no cultivo, no plantio"

Na educação do campo, é comum a referência à formação técnica para trabalhos no campo. A fala que nomeia este zoom é de uma professora de matemática, que foi entrevistada por mim (Barbosa, 2014):

Mas, assim, o que eu acho que poderia ser diferente, o que poderia ser para ficar melhor é tendo esses projetos voltados para eles, porque como está lá dentro do assentamento, acho que deveria ter, porque lá, às vezes eles não têm muito acesso a certas coisas, [...] acho que deveria ter, assim, a escola poder ajudar nessa formação deles, ajudar na família, no cultivo, no plantio, melhor... eu acho que seria interessante.

Assim, este zoom trata dos entendimentos a respeito da escola do campo que sugerem que ela (também) tenha uma formação técnica voltada para o meio rural. É, então, mais um objetivo da escola do campo: auxiliar na formação para o trabalho com o campo. Com a inclusão desse objetivo ao currículo escolar, alteram-se os métodos, os conteúdos, os materiais e as formas de avaliação, já que uma nova proposta está colocada para essas escolas.

Grande parte dos trabalhos presentes no corpus aborda cursos técnicos. Um exemplo é o artigo do ENEM, de Toledo (2016), que trata do curso técnico em Agropecuária na Escola Agrotécnica Federal de Sertão (EAFS), na década de 1980. A autora mostra a importância da prática, no discurso para a formação profissional:

O fragmento "meio turno nós estudávamos e meio turno nós tínhamos prática. No turno inverso, eram as técnicas, sempre tinha introdução e depois as práticas" mostra como o currículo da EAFS era organizado de forma que tanto as aulas teóricas quanto as aulas práticas tinham o seu espaço nas disciplinas técnicas. A fala do egresso, quando expressa que "não existe aprender sem prática", demonstra que essa era a verdade que circulava na época e que era tomada pelos alunos como necessária para a formação de um profissional do setor agropecuário apto para enfrentar os desafios diários postos pela profissão (Toledo, 2016, p. 6).

Por outro lado, esse discurso não se mantém na disciplina de matemática:

Desse modo, a educação matemática presente no currículo da disciplina de Matemática na EAFS, especificamente nos anos 1980, não seguia o princípio de ensino "aprender a fazer fazendo" que na época conduzia a organização curricular e as práticas pedagógicas de todas as Escolas Agrotécnicas Federais do Brasil (Toledo, 2016, p. 11).

Mas, mesmo tratando-se de formação na escola básica, em alguns trabalhos, há a sugestão de uma formação que auxilie no trabalho no campo, como na tese de Silva (2011, p. 26), em que há um relato histórico da Escola Normal Rural, prezando o conhecimento técnico voltado para o meio rural:

Assim levava os seus alunos, desde o curso primário, ao campo da cultura do estabelecimento de ensino, para as aulas práticas de jardinagem, horticultura, pomicultura, criação de abelhas, de aves e de outros animais domésticos, além das aulas de pequenas indústrias e trabalhos manuais [...]. 
Há, também, uma crítica quando isso não ocorre, como na dissertação de Santos (2010, p. 62): “Apesar de sua população considerar a escola importante para o seu desenvolvimento, percebemos, nas falas dos entrevistados, que a mesma funciona apenas como uma formalidade, sem maiores consequências para o dia-a-dia dos trabalhadores".

Neste zoom, estão presentes, também, trabalhos que sugerem que, em escolas do campo, os estudantes poderiam cultivar alimentos em uma horta. A dissertação de Amarante (2011, p. 51), por exemplo, relata a situação de uma escola, em que os estudantes são responsáveis pela horta da escola, que fornece alimento para a merenda: "A merenda das escolas era produzida utilizando alguns legumes e vegetais produzidos na horta e os próprios alunos eram responsáveis por cuidarem do plantio, de regar e de colher o que era produzido".

Esse trecho, situado no contexto da escola apresentada na dissertação - de uma escola em regime multisseriado, contando com a infraestrutura precária de uma sala de aula, uma cozinha, um banheiro e área livre, em que secretaria e diretoria funcionam dentro da sala de aula (Amarante, 2011, p. 50) - causou-me preocupação: qual a verdadeira intenção com a horta produzida pelos estudantes?

É possível que tenha havido um planejamento dos envolvidos na escola, isto é, direção, coordenação, professores e, especialmente, pais, em que se concluiu que é importante para a formação desses estudantes a produção de uma horta e, consequentemente, os legumes e vegetais podem ser aproveitados na merenda escolar. Porém, é possível, por outro lado, que a precariedade da escola faça com que a horta seja um meio importante para garantir a merenda dessas crianças ou que a economia de verbas para alimentação disponibilize recursos para outras necessidades da escola - que, conforme descrição da autora, são muitas.

O que diferencia uma escolha consciente, feita para a formação dos estudantes, de uma escolha influenciada por questões econômicas é uma linha tênue.

Não quero, com isso, desmerecer o caráter formativo de uma horta. Entendo que, sim, como outras atividades diversas desenvolvidas no ambiente escolar, uma horta pode propiciar situações educativas. Um exemplo é o relatado por Camini (2009, p. 42), sobre as escolas itinerantes do MST:

Uma horta com variedade de verduras e plantas medicinais traz presente a experiência já vivida por estes sujeitos, quando em algum lugar tiveram a oportunidade de cultivar a terra. É um sinal, juntamente com o jardim, do modelo de assentamento, de casa, que escola e que projeto de educação do campo querem construir.

Nesse caso é uma decisão pautada em princípios do próprio movimento social, ou seja, tem caráter formativo. Vê-se que, nesse relato, há uma intencionalidade educacional na horta. Será que o mesmo vale para escolas do campo públicas, mantidas por prefeituras, muitas vezes em situação de escassez de recursos? Como diferenciar o trabalho no campo como princípio educativo do trabalho infantil? São questões que coloco para reflexão. 
Assim, este zoom reúne pesquisas que indicam a importância da formação técnica para o trabalho no meio rural no contexto da educação do campo. Os autores entendem que seria importante que os estudantes do campo fossem preparados, nas escolas, para o trabalho em seu ambiente, no caso, rural, seja para ajudar os familiares em seus trabalhos ou para futuros empregos que possam almejar.

\section{Considerações finais}

Com esta pesquisa, relatada aqui, pude mapear, em produções acadêmicas, formas de se entender o currículo de matemática na educação do campo.

Primeiramente, constituí imagens panorâmicas sobre essas produções. Para tal, fiz um levantamento de publicações sobre educação do campo no periódico BOLEMA, no período de 1985 a 2016, nos anais do ENEM, de 1987 a 2016, e nas dissertações e teses presentes no banco de teses da CAPES, produzidas de 2002 a 2016.

A esse respeito, destaco algumas considerações: (i) nos últimos anos, houve um aumento significativo de publicações que aproximam a educação do campo e a educação matemática - o que, possivelmente, se deva às ações dos movimentos sociais no final dos anos 1990 e consequentes políticas públicas, e à criação de cursos de Licenciatura em Educação do Campo, com o lançamento de editais, por parte do Ministério da Educação, nos anos de 2009 e de 2012; (ii) há uma concentração das pesquisas de pós-graduação com essa temática no nível de mestrado e, geograficamente, nos estados do Rio Grande do Sul e de São Paulo; (iii) nas pesquisas mais recentes, estão presentes trabalhos oriundos do PROFMAT, que se distinguem em seus objetivos das pesquisas da área de Educação Matemática, enfatizando questões matemáticas; (iv) há uma presença importante de pesquisas que tratam de cursos técnicos voltados para o campo, possivelmente, influenciada pela ampliação da Rede Federal de Educação Profissional, Científica e Tecnológica.

A partir desses panoramas, constituí as imagens com zoom, que possibilitaram a discussão sobre aspectos relevantes do currículo escolar, especificamente de matemática, na educação do campo. Notei que há pouco consenso sobre essa temática nas publicações; por outro lado, identifiquei quatro discursos recorrentes: "Quando eu vou, às vezes, dar um exemplo, eu começo a citar boi, hortaliças, verdura", "Vamos aos saberes locais, porque eles também foram acumulados pela humanidade", "Matemática é matemática, ou tem matemática do campo?” e "A escola poder ajudar nessa formação deles, ajudar na família, no cultivo, no plantio". Em cada zoom, pude debater os discursos com trechos diversos das publicações analisadas.

\section{Referências}

Amarante, A. A. (2011). O uso do Tinkerplots para exploração de dados por professores de escolas rurais. Dissertação de Mestrado em Educação Matemática e Tecnológica. Recife: Universidade Federal de Pernambuco. 
Antunes-Rocha, M. I. (2009). Licenciatura em Educação do Campo: histórico e projeto político-pedagógico. In Antunes-Rocha, M. I.; Martins, A. A. Educação do Campo: desafios para a formação de professores (pp. 39-55). Belo Horizonte: Autêntica.

Barbosa, L. N. S. C. B., Carvalho, D. F. \& Elias, H. R. (2014). As relações estabelecidas entre o cotidiano camponês e a sala de aula: análise da produção científica em 10 edições do Encontro Nacional de Educação Matemática. Revista de Educação Matemática e Tecnológica Iberoamericana, Recife, 5(1), 1-21.

Barbosa, L. N. S. C. (2014). Entendimentos a respeito da matemática na educação do campo: questões sobre currículo. Tese de Doutorado em Educação Matemática. Rio Claro: Univ Estadual Paulista.

Basso, J. D. \& Bezerra Neto, L. (2012). As contradições presentes nas reivindicações do Movimento por uma Educação do Campo e a Pedagogia Histórico-Crítica. Itinerarius Reflectionis, Jataí, 2(13), 1-15.

Bourdieu, P. (2007). A escola conservadora: as desigualdades frente à escola e à cultura. In: Nogueira, M. A.; Catani, A. (Org.) Escritos da Educação (pp. 39-64). Petrópolis: Vozes.

Ministério da Educação (MEC). (2002). Resolução $n^{o} 1$, de 3 de abril de 2002. Institui Diretrizes Operacionais para a Educação Básica nas Escolas do Campo. Diário Oficial República Federativa do Brasil, Brasília.

Ministério da Educação (MEC). (2008). Resolução $n^{o}$ 2, de 28 de abril de 2008. Estabelece diretrizes complementares, normas e princípios para o desenvolvimento de políticas públicas de atendimento da Educação Básica do Campo. Diário Oficial República Federativa do Brasil, Brasília.

Secretaria de Educação Continuada, Alfabetização e Diversidade (SECAD) (2009). Edital de Convocação $n^{\circ}$ 09, de 29 de abril de 2009. Diário Oficial República Federativa do Brasil, Brasília.

Secretaria de Educação Continuada, Alfabetização e Diversidade e Inclusão (SECADI). (2012). Edital de Chamada Pública $n^{\circ} 2$, de 31 de agosto de 2012. Diário Oficial República Federativa do Brasil, Brasília.

Camini, I. (2009). Escola itinerante dos acampamentos do MST: um contraponto à escola capitalista? Tese de Doutorado em Educação Porto Alegre: Universidade Federal do Rio Grande do Sul.

Caldart, R. S., Pereira, I. B., Alentejano, P., \& Frigotto, G. (Org.) (2012). Dicionário da Educação do Campo. Rio de Janeiro, São Paulo: Escola Politécnica de Saúde Joaquim Venâncio, Expressão Popular.

Caldart, R. S. (2009). Educação do Campo: notas para uma análise de percurso. Trabalho, Educação e Saúde, Rio de Janeiro, 7(1), 35-64.

Caldart, R. S. (2012). Pedagogia do Movimento Sem Terra. (4a ed). São Paulo: Expressão Popular.

Costa, L. F. M. (2012). A etnomatemática na educação do campo, em contextos indígena e ribeirinho, seus processos cognitivos e implicações à formação de professores. Dissertação de Mestrado em Educação em Ciências na Amazônia. Manaus: Universidade do Estado do Amazonas. 
D’Ambrosio, U. (2004). Etnomatemática e Educação. In Knijnik, G., Wanderer, F. \& Oliveira, C. J. Etnomatemática: currículo e formação de professores (pp. 39-52). Santa Cruz do Sul: EDUNISC.

Feyh, C. R. N. (2013). Modelagem matemática na educação do campo. Dissertação de Mestrado em Ensino de Ciências Naturais e Matemática. Blumenau: Universidade Regional de Blumenau.

Fontana, D. L. (2006). Adaptações no ensino de matemática: uma análise da prática dos educadores do campo. Dissertação de Mestrado em Educação. Curitiba: Universidade Federal do Paraná.

Instituto de Pesquisa Econômica Aplicada (IPEA). (2015). II PNERA: Relatório da II Pesquisa Nacional sobre a Educação na Reforma Agrária. Brasília: IPEA.

Instituto Nacional de Estudos e Pesquisas Educacionais Anísio Teixeira (INEP). (2007). Panorama da educação do campo. Brasília: Instituto Nacional de Estudos e Pesquisas Educacionais Anísio Teixeira.

Justi, J. C., \& Bennemann, M. (2016). Etnomatemática: uma proposta pedagógica contextualizada. Anais do Encontro Nacional de Educação Matemática (pp. 1-12). São Paulo, SP, Brasil, 12.

Knijnik, G. (2001). Educação Matemática, Exclusão Social e Política do Conhecimento. Bolema, Rio Claro, 14(16), 1-15.

Knijnik, G. (2004a). Etnomatemática e politicidade da Educação Matemática. Anais do Congresso Brasileiro de Etnomatemática, Natal, RN, Brasil, 2. Disponível em: http://www2.fe.usp.br/ etnomat/site-antigo/anais/GelsaKnijnik.html.

Knijnik, G. (2004b). Itinerários da Etnomatemática: questões e desafios sobre o cultural, o social e o político na educação matemática. In Knijnik, G.; Wanderer, F.; Oliveira, C. J. Etnomatemática: currículo e formação de professores (pp. 19-38). Santa Cruz do Sul: EDUNISC.

Kniknik, G., \& Duarte, C. G. (2010). Entrelaçamentos e Dispersões de Enunciados no Discurso da Educação Matemática Escolar: um estudo sobre a importância de trazer a "realidade" do aluno para as aulas de matemática. Bolema, Rio Claro, 23(37), 863-886.

Lima, A. F. C., \& Carvalho, D. L. (2010). Relacionando conhecimentos matemáticos do contexto rural e os do contexto escolar em aulas de matemática dos três anos finais do Ensino Fundamental. Anais do Encontro Nacional de Educação Matemática (pp. 1-8). Salvador, BA, Brasil, 10.

Lopes, R. M. G. (2016). O trieiro, o Narrador e suas histórias. Anais do Encontro Nacional de Educação Matemática (pp. 1-9). São Paulo, SP, Brasil, 12.

Lopes Filho, F. D. (2014). Os saberes matemáticos presentes nas práticas agrícolas em Tamatateua e a relação com o saber escolar. Dissertação de Mestrado em Linguagens e Saberes da Amazônia. Bragança: Universidade Federal do Pará.

Matos, E. A. (2014). Proposta de material didático sobre função afim específico para o curso de Agroecologia. Dissertação de Mestrado em Matemática em Rede Nacional. Mossoró: Universidade Federal Rural do Semi-Árido.

Moraes, R. \& Galiazzi, M. C. (2007). Análise Textual Discursiva. Ijuí: Unijuí.

Zetetiké, Campinas, SP, v.26, n.2, mai./ago., 2018, p.404-422

ISSN 2176-1744 
Munarim, A. (2008). Movimento Nacional de Educação do Campo: uma trajetória em construção. Anais da Reunião Anual da Associação Nacional de Pós-Graduação e Pesquisa em Educação (pp. 1-17). Caxambu, MG, Brasil, 31.

Oliveira, H. D. L. (1998). Unidades populares de medida de comprimento e área: o rural e o currículo escolar. Anais do Encontro Nacional de Educação Matemática (pp. 215-217). São Leopoldo, RS, Brasil, 6.

Sachs, L. (2017). Teorias curriculares e implicações pedagógicas da etnomatemática no contexto da educação do campo. In K. A. Silva \& J. O. Dalto, Educação Matemática e Pesquisa: algumas perspectivas (pp. 297-318). São Paulo: Livraria da Física.

Sachs, L., \& Elias, H. R. (2016). A Formação Matemática nos Cursos de Licenciatura em Educação do Campo. Bolema, Rio Claro, 30(55), 439-454.

Santos, L. M. S. (2010). Cálculo de área na vida e na escola: possíveis diferenças conceituais. Dissertação de Mestrado em Educação. São Cristóvão: Universidade Federal de Sergipe.

Saviani, D. (2011). Pedagogia histórico-crítica: primeiras aproximações. Campinas: Autores Associados.

Seckler, D. M. (2010). O ensino de função polinomial do $1^{o}$ grau na oitava série do Ensino Fundamental: um trabalho com situações do cotidiano. Dissertação de Mestrado Profissionalizante em Ensino de Física e de Matemática. Santa Maria: Centro Universitário Franciscano.

Silva, M. V., Marques, M. R. A., \& Gandin, L. A. (2012). Contradições e ambiguidades do currículo e das políticas educacionais contemporâneas - entrevista com Michael Apple. Currículo sem Fronteiras, Porto Alegre, 12(1), 175-184.

Silva, P. S. P. (2011). A formação de professores(as) na Escola Normal Rural de Juazeiro do Norte/CE sob uma perspectiva Etnomatemática. Tese de Doutorado em Educação Matemática. São Paulo: Universidade Bandeirante de São Paulo, São Paulo.

Silva, T. T. (2010). Documentos de Identidade: uma introdução às teorias do currículo. (3a ed). Belo Horizonte: Autêntica.

Souza, R. B. (2016). Programa Etnomatemática: análise de práticas pedagógicas de ensino de matemática no contexto de educação no/do campo. Anais do Encontro Nacional de Educação Matemática (pp. 1-12). São Paulo, SP, Brasil, 12.

Thiesen, J. S., \& Oliveira, M. A. (2012). O lugar do currículo na/da educação do campo no Brasil: aproximações e teorias curriculares. Revista Educação Pública, 21(45), 13-28.

Toledo, N. T. (2016). Educação matemática e a formação do técnico agrícola: uma análise de uma escola gaúcha na década de 1980. Anais do Encontro Nacional de Educação Matemática (pp. 1-12). São Paulo, SP, Brasil, 12. 